\title{
BALANZAS Y ROMANAS DE BRONCE EN LOS MERCADILLOS DE ANTIGUEDADES DE SEVILLA
}

\author{
POR \\ FERNANDO FERNANDEZ GOMEZ (*)
}

RESUMEN Se presentan diversos ejemplares de balanzas y romanas de bronce, localizados unos en los mercados de antigüedades de Sevilla y conservados otros en su Museo Arqueológico, analizándose su estructura y las variaciones que presentan sus barras graduadas. Se completa el estudio con una selección de pesas y contrapesos de la misma procedencia.

ABSTRACT We present here several examples of Roman balances and steel-yards, some of them found in the antiquities market of Sevilla, and others conserved in its Archaeological Museum. Their structure and the variations of their scales are analized. The study is completed with a selection of weights from the same source.

Palabras clave Mercado antigüedades. Sevilla. El Saucejo. Itálica, Osuna. Balanzas. Romanas. Libras. Onzas. Bellota. Dado. Bronce. Plomo. Pesas. Contrapesos.

Key words Antiquities market. Sevilla. El Saucejo. Itálica. Osuna. Balances. Steel-yards. Pound. Ounce. Acorn. Die. Bronze. Lead. Steelyards weights.

Si paseamos por los mercadillos de antigüedades de nuestra provincia, es fácil tropecemos a veces con piezas que gustosos adquiriríamos si fuera posible para nuestros museos, pero que con dolor tenemos que ver marchar, por cantidades a veces irrisorias, rumbo a destinos desconocidos, en donde se perderán para siempre, sin que nunca vaya a saberse ni siquiera que proceden de nuestra tierra. Procuramos por ello, siempre que es posible, y no siempre lamentablemente lo es, documentarlas, para que quede al menos constancia de que fueron halladas en ella. Algunas de estas piezas son las que ahora presentamos. Se trata de tres romanas de bronce de distinto tamaño, elementos sueltos de un par de balanzas, y numerosas pesas y contrapesos de unas y de otras.

Comenzaremos hablando del ejemplar de menor tamaño que hemos conocido. Es una pequeña romana con doble punto de apoyo y doble, por tanto, cara de lectura en su barra, de sección ésta

(`) Director del Museo Arqueológico de Sevilla (Plaza de América s/n, 41013-Sevilla). 
ligeramente rómbica, rematada en su extremo en un pequeño engrosamiento de tendencia esférica. $\mathrm{Al}$ extremo opuesto, donde la barra se ensancha y toma forma rectangular, ofrece dos perforaciones, una en la parte superior y otra en la inferior, sobre protuberancias, a las cuales quedan sujetas sendos ganchos, de la anchura de un dedo, para servir como elemento de sostén. Y aún más allá una tercera, de la que cuelgan dos ganchos sujetos mediante cadenillas, que servirían para dejar los objetos suspendidos (Fig. 1).

La barra graduada es muy corta, $110 \mathrm{~mm}$., y está dividida por un lado en 5 partes iguales, de I a $\mathrm{V}$ libras, mientras por el opuesto, al acercarse el punto de apoyo, llega a las XXIII, indicando numéricamente primero el $\mathrm{V}$, que coincide en las dos caras, después el $\mathrm{X}$, el quince con solo la $\mathrm{V}$, a continuación el XX, y finalmente el XXIII por medio solo de las unidades. Entre cifra y cifra aparecen marcadas, por la parte superior, una serie de muescas para indicar los valores intermedios. En ellas reposaría el contrapeso en forma de bellota que forma parte de la romana, con ayuda de la anilla de que se le ha provisto, por medio de un simple alambre, anudado sobre sí mismo, para correr libremente a lo largo de la barra. Aunque este contrapeso parece de bronce, en realidad debe estar relleno de plomo, a juzgar por la perforación que muestra en la parte superior, por donde sin duda ha sido cebado hasta alcanzar el peso requerido para el buen funcionamiento de la romana, 286 gramos.

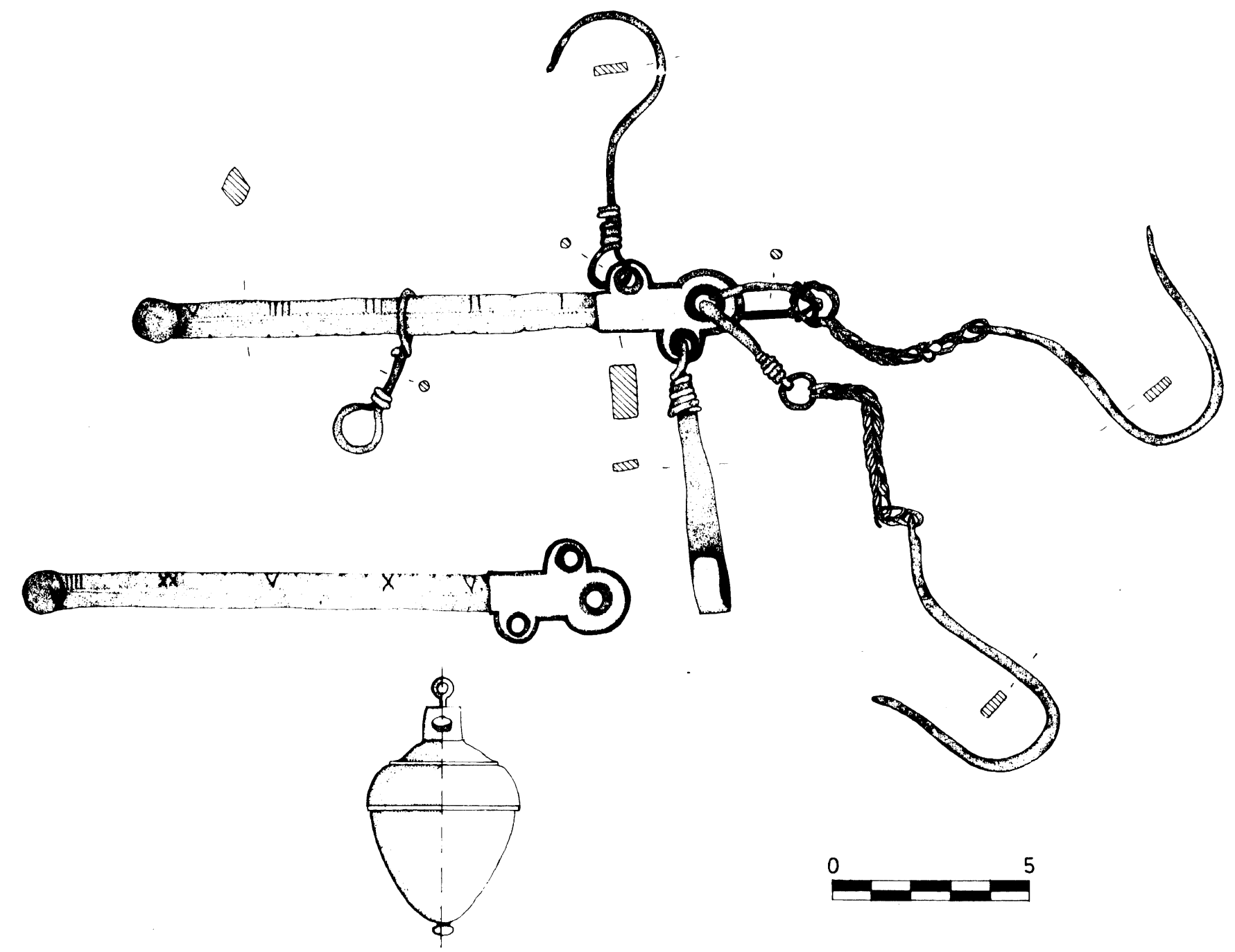

FIG. 1._Romana de El Saucejo (Sevilla). 
La relación distancia entre muescas/valor del peso señalado es muy irregular, y cuesta trabajo admitir pudieran conseguirse pesos con un mínimo de exactitud como para poder entenderse. Sucede ésto sobre todo en la cara que marca de V a XXIII libras, en la que las variaciones llegan desde $3.5 \mathrm{~mm}$., entre VIII y IX, hasta los 6.5, entre XII-XIII y XVI-XVII. Y éso que parece haberse intentado grabar marcas exactas, por medio de puntos complementarios, pero que en realidad no es mucho lo que aportan.

La pieza había sido hallada, al parecer, en el lugar conocido como Diente de la Vieja, en el tr. mino municipal de El Saucejo, en el mismo yacimiento que las famosas tablas de la Lex Irnitana, a unque no en el poblado, sino en la necrópolis, formando parte de un ajuar funerario, en el cual se hallaban tambien diversas monedas del siglo I d. C.

Su estado de conservación es muy bueno. Está completa y cubierta por una bonita pátina olivácea. Las cadenillas de sustentación de la carga, partidas por el óxido. Los ganchos en que quedan rematadas, con algunas exfoliaciones.

La segunda romana es de mayor tamaño, pero lamentablemente de ella solo hemos conocido la barra graduada, con triple punto de apoyo, y triple, por consiguiente, cara de lectura, que llega en teoría desde 1 onza hasta 42 libras, casi el doble de capacidad que la anterior, pero con más posibilidades de ser exacta que ella, pues mientras la graduación de aquélla solo llegaba a $220 \mathrm{~mm}$., ésta alcanza los 810, entre sus tres caras, de lo que puede deducirse que estuviera destinada a pesar productos de mayor valor, lo que parece contradecirse con su tamaño. Por lo demás, la barra es muy similar, de sección rómbica, rematada en sus extremos con apéndices de tendencia esférica, en ésta más individualizados. La cabeza es también más larga, $100 \mathrm{~mm}$. exactos, y aquí no con perforaciones coincidiendo con protuberancias, sino con oquedades atravesadas por roblones de los que colgarían los ganchos correspondientes a cada una de las caras graduadas. Uno se halla a los $19 \mathrm{~mm}$. del comienzo de la barra, de su valor cero. Otro, a los 52 . Y el tercero, a los $82 \mathrm{~mm}$. Prácticamente, por tanto, equidistantes (Fig. 2).
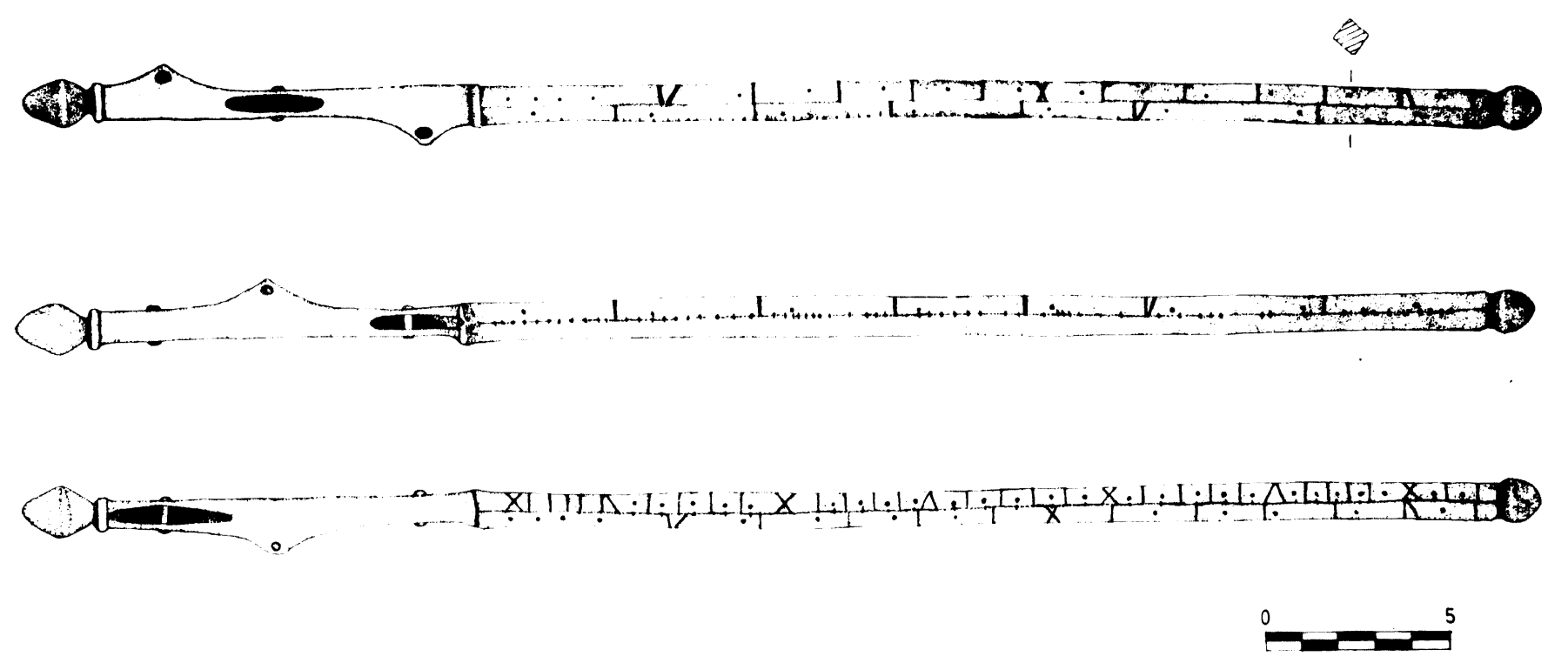

Fig. 2.-Romana del Museo Arqueológico de Sevilla. 
La graduación de la barra está realizada de manera muy sencilla, desempeñando en ella las muescas un papel de gran importancia, pues en la primera cara todas las unidades, hasta V, aparecen como simples I, lo mismo que el valor VI, máximo número de libras enteras que alcanza, pues, aunque la capacidad de pesaje marcada llega en realidad hasta 7 libras, solo se expresan aquí las onzas, indicadas por simples muescas en la arista correspondiente de la barra, con relación a la cual el V quedaría invertido, para facilitar sin duda su lectura desde determinada posición.

La segunda cara graduada abarca desde las 4.1 hasta las 16 libras, apareciendo como únicos guarismos expresamente señalados el V, el X y el XV, éste con solo la V, muy abierta en su base, casi como dos II. Los valores intermedios completos son siempre I, y las mitades puntos en el centro de la regla.

La tercera cara presenta mayor complejidad, pues, a primera vista, los numerales parecen agolparse en ella. El primer valor indicado es el XIIII. A continuación el XV, con solo la V, como es habitual. El XX con una sola X. Y así sucesivamente, hasta las 42 libras, series de X, V y I. Y puntos para las mitades.

La relación distancias/valores indicados en este ejemplar, cuyo contrapeso corre de izquierda a derecha, es también muy arbitraria. En la primera cara, de 0 a 6 libras, las marcas indicativas de los distintos valores quedan separadas entre 35, de III a IV, y $49 \mathrm{~mm}$., de V a VI. Como este mismo valor se repite en la segunda cara, podría quizá prescindirse de él, y la oscilación se reduciría entonces de 39 a $49 \mathrm{~mm}$., distancia entre el comienzo de la barra graduada y I.

Parecidas oscilaciones vemos en la segunda cara graduada, que sirve para pesar entre V y XV libras, y en la que las distancias entre muescas varian entre los $16 \mathrm{~mm}$. de las X-XI libras, y los 24.5 de las V-VI, cuando la distancia media correcta debía hallarse en los $20.05 \mathrm{~mm}$.

Las variaciones se repiten en la tercera cara de la barra, graduada entre XV y XLII libras. La separación correcta entre valores debía hallarse en $8.77 \mathrm{~mm}$., pero en realidad oscila entre los 6 mm. de XXXVI-XXXVII y XXXVIII-XXXIX, y los 12 de XV-XVI libras.

Todas las caras presentan, por tanto, una irregularidad muy llamativa, que nos hace preguntarnos de nuevo cómo podría llevarse a cabo con exactitud el pesaje de los productos, pero que no es exclusiva de nuestros ejemplares, sino frecuente en todos ellos. Algunos presentan incluso curiosos vacíos, como el de la Walter Art Gallery, de Baltimore, con tres caras graduadas también, de las cuales la segunda llega hasta las 17 libras y la tercera no empieza hasta las 20.

Una de estas cabezas de romana hemos encontrado también en los mercadillos y depositado en nuestro Museo. Conserva solo el extremo de la barra, con uno de los ganchos, el más alejado. Falta otro, del que solo aparece su arranque, y toda la regla graduada, intencionadamente cortada de antiguo, como denuncian los golpes que aparecen en la parte conservada, quien sabe si para inutilizarla por su falta de precisión, la cual era vigilada y controlada por las correspondientes autoridades municipales (Fig. 3).

El último ejemplar que vamos a presentar aquí, en homenaje a nuestro querido amigo, colega y maestro, el Dr. Veny, con quien realizamos, en Menorca, nuestras primeras excavaciones arqueológicas, es una pieza realmente espectacular. También de bronce, alcanza la barra en su conjunto una longitud de $44.3 \mathrm{~cm}$., de los cuales los 11.2 primeros corresponden a la cabeza, los 31.7 siguientes al espacio graduado, y los 1.4 restantes al botón cónico en el que aquélla queda rematada (Fig. 4).

De la cabeza cuelgan tres cadenillas, terminadas en amplios ganchos de extremos doblados en forma de cabezas de pato esquemáticas, que servirían para colgar la romana en tres posiciones distintas. La primera sirve para pesar entre 5 y 16 libras, sin más valor indicado que el $\mathrm{V}$ inicial en el extremo de la barra. Los restantes solo por medio de rasgos incisos, largos, transversales a ella, cruzándola por completo. Muy cortos, por el contrario, hasta el punto de verse alguno con dificultad, por el desgaste producido en la regla por el uso, las onzas. Entre unos y otros, señalados con tres puntos encima, en forma de triángulo, las medias libras, con algunos errores, pues hay puntos también al lado del rasgo que indica las 9 libras, en lo que serían 8 libras y 11 onzas, y también más allá de las 10, en las 10.20, y en las 10.90 libras. Y faltan, por el contrario, en las 10.5 libras. Las 14 
libras no están marcadas por una incisión sino por una línea de puntos, apoyada en un par de puntos y coronada por otro.

La segunda cara corresponde al gancho intermedio. No presenta ningún valor numérico. Tras un tramo inicial exento, comienzan la serie de incisiones, largas y cortas. Aquéllas separadas entre sí alrededor de $15 \mathrm{~mm}$., y cada uno de los espacios dividido a su vez en cuatro partes iguales, expresadas por pequeñas muescas. Sobre la central, tres puntos dispuestos en forma de triángulo, como en la otra cara, y como en ella indicaría las medias libras. Las muescas sencillas, los cuartos de libra. Si tenemos en cuenta que la cara anterior llegaba a las 16 libras, éste sería teóricamente el valor que debía aparecer en esta cara, con lo cual se podrían medir en ella hasta las 33 libras.

La tercera cara graduada comienza de nuevo con una V expresamente indicada. Para no dejar vacíos intermedios, hemos de pensar que corresponde a las 25 libras, y la serie de muescas en que se divide, una larga cada cinco cortas, a libras completas, con lo cual la capacidad de pesaje de la romana llegaría a las 85 , con algunas irregularidades como en otras ocasiones. Por ejemplo, que el valor 35 no lo marque una muesca larga sino corta, aunque mas gruesa que las restantes y entre dos líneas de puntos, que no sabemos si pretenden indicar algo. Otros hay en el probable valor 50, sueltos, y sobre el 65, aunque aquí dispuestos en forma de V, por debajo de la incisión vertical. Pensamos si podrán ser marcas de valor provisionales, o correctoras, pues aparecen también por debajo del $\mathrm{V}$ inicial y de la marca de las 30 libras, coincidiendo con los trazos incisos. Para indicar las 75 libras no se presenta un solo rasgo vertical largo, sino dos, separados entre sí un par de milímetros.

Estas irregularidades no son las únicas que observamos en la barra, ni las de mayor interés. Nos llaman más la atención las que, como en los casos anteriores, afectan a la graduación de la barra y a su falta de exactitud.
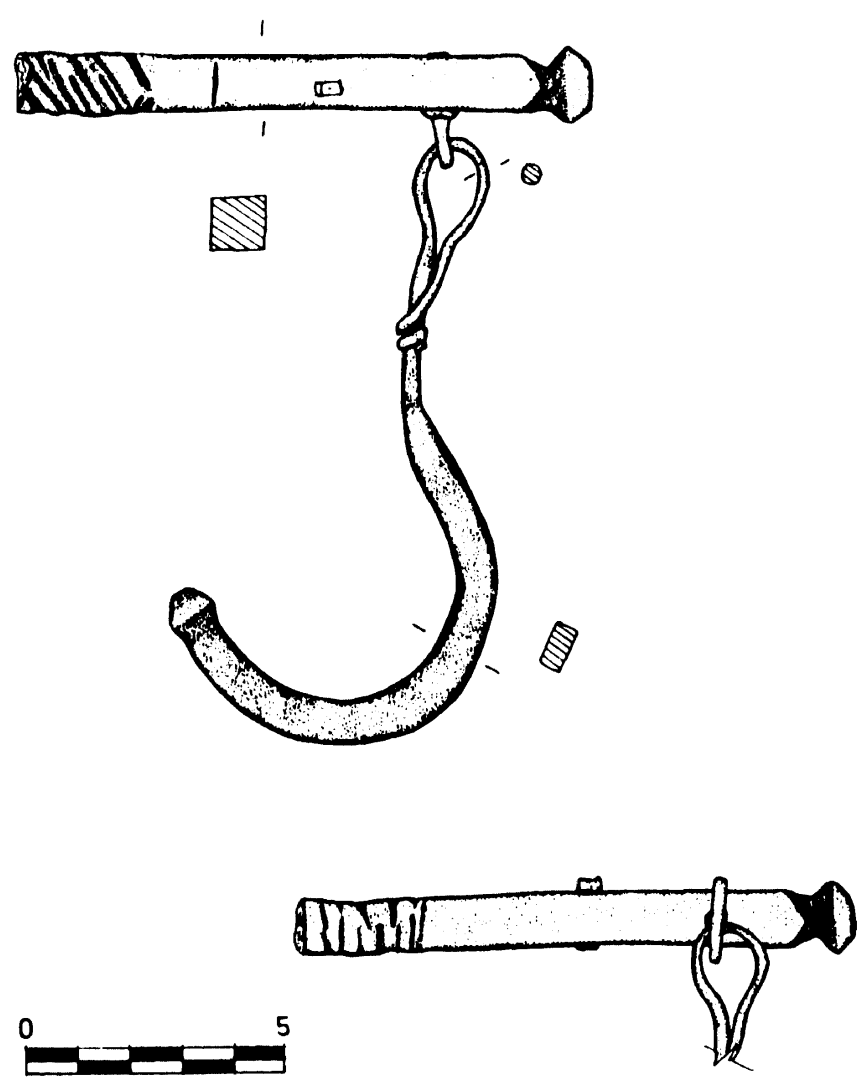

FIG. 3.-Fragmento de romana del Museo Arqueológico de Sevilla. 

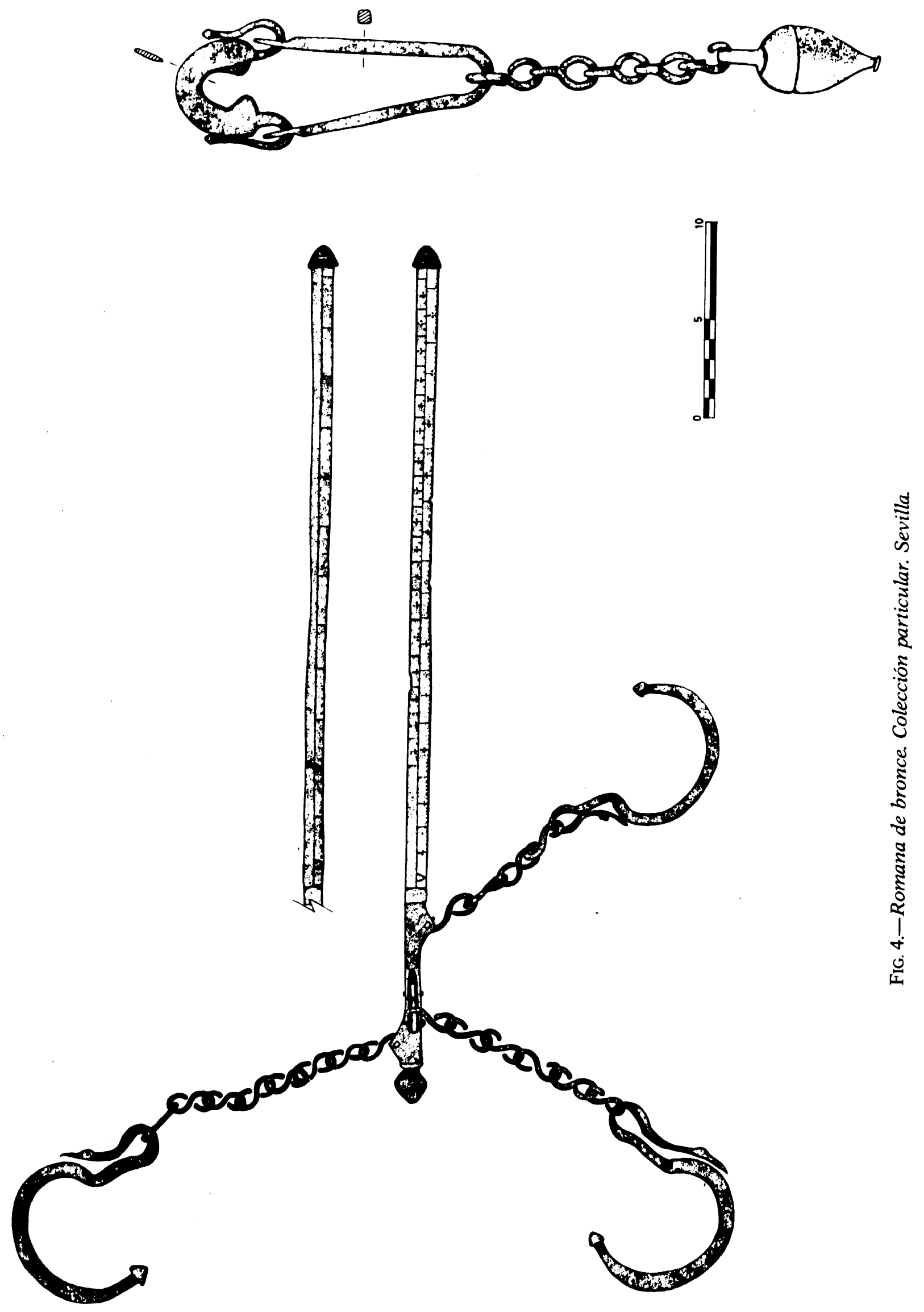

T. P., $1991, \mathrm{n}^{\circ} 48$

(c) Consejo Superior de Investigaciones Científicas

http://tp.revistas.csic.es Licencia Creative Commons 3.0 España (by-nc) 
Así, en el tramo inicial, las libras debían ocupar teóricamente, espacios de $28 \mathrm{~mm}$., pero mientras en unas ocasiones apenas los alcanzan, en otras llegan a ser 31 ó 32, por ejemplo entre las 11-12 y las 14-15 libras. En la segunda cara, las libras tendrian que estar separadas exactamente la mitad, $14 \mathrm{~mm}$., pero hay tramos que no superan los $11 \mathrm{~mm}$., los correspondientes a las 23-24 y 28-29 libras, mientras otros alcanzan los 16, las 19-20 y las 28-29 libras, y hasta los $17 \mathrm{~mm}$., las 20-21 libras, con una enorme desviación en este último caso, incluso para medir las medias libras, pues la primera mitad solo llega a los $7.5 \mathrm{~mm}$., en tanto que la segunda, responsable del error, ocupa los 9.5 restantes. Esto no suele ser, sin embargo, frecuente, ya que las mitades aparecen casi todas en el centro de los tramos correspondientes.

En la tercera cara, las libras deberían ocupar solo $5 \mathrm{~mm}$., pues la graduación de la barra tiene una longitud de $30 \mathrm{~cm}$. y vale para 60 libras. Hay valores que no pasan, sin embargo, de los 3, las 30-31 libras, e incluso de los $2 \mathrm{~mm}$., las 44-45 libras. Otros, por el contrario, llegan a los 7, las 28-29 libras, por poner solo algunos ejemplos. Tan amplia oscilación nos hace pensar que solo se utilizaran los pesos redondeados, de 5 en 5 libras, cuyos tramos deberían alcanzar, y de hecho alcanzan todos, los $25 \mathrm{~mm}$. La única excepción serían las 45-50 libras, que solo llegan a los $23 \mathrm{~mm}$. A este posible deseo de exactitud en estos tramos se debería la presencia del doble rasgo vertical en las 75 libras. El segundo de ellos, en las 75.5 libras, habría quedado anulado. Y explicaría que alguno de los tramos, el de las 40-45 libras, esté incluso dividido en 6 partes y no en 5, pues las divisiones pequeñas no parecen tener mayor interés. Aquí es, por otra parte, donde observábamos el error de los $23 \mathrm{~mm}$. en las 5 libras, y de la libra que solo ocupaba $2 \mathrm{~mm}$., y pensamos si esa muesca de solo $2 \mathrm{~mm}$., aunque sea corta, no querrá rectificar el error, con lo cual se regularizarían los tramos y desaparecería ese sexto divisor intrusivo.

La romana se completa con su pilón, una bellota de 302.28 gr., rematada en un apéndice cilíndrico que la sujeta a una curiosa estructura en $U$ invertida, cerrada por un puente articulado sobre sus extremos, que le permite correr libremente por la barra, pero no salirse de ella. El peso de esta estructura es de 209.17 gr. En conjunto, pues, $511.45 \mathrm{gr}$.

El estado de conservación de la pieza es extraordinario. Completa en todos sus detalles, ganchos, cadenas, pasadores, - cubierta de una bonita pátina verdosa en distintos tonos, dejando aparecer el bronce en algunas zonas, y sin ningún foco de óxido. En determinados puntos se observan, adheridos, restos de óxido de hierro. Se constatan asimismo señales de desgaste por el uso en la propia barra, sobre todo en su zona central, donde se presenta igualmente un fallo de fundición en la arista que corresponde a los pesos más bajos.

Balanzas y romanas son elementos muy frecuentes en todo el mundo romano y a lo largo de toda su historia, sobre todo a partir de la decisión de Augusto de imponer en todo el Imperio el sistema romano de pesas, medidas y monedas, lo que habría de facilitar enormemente las relaciones comerciales (1).

Mucho más ajustados y fáciles de controlar que los de las romanas, podían ser los pesos efectuados en las antiguas balanzas de brazos iguales, cuyos valores venían dados por los de los correspondientes contrapesos. Tenían, sin embargo, el inconveniente de que era necesario disponer, y en su caso transportar, mayor cantidad de contrapesos, tantos como pudiera pesar la carga más pesada posible, por lo que fue cayendo poco a poco en desuso, hasta quedar reducida de hecho su

(1) Los últimos ejemplares que hemos conocido han sido los publicados por J. Alarçao y otros. Fouilles de Conimbriga, VII, Trouvailles diverses. Conclusions generales, Paris, 1979: 175; C. Aranegui Gascó, «Statera romana hallada en Valencia», Archivo de Prehistoria Levantina, XIX, 1989: 263; P. M. Barford, K. Blockeley y M. Day, «A romano-british steelyard from Marshfield, Avon", AJ, LXIV, 1984: 397; F. Chaves Tristán, "Instrumentos de medida romanos hallados en Andalucía", Zephyrus, XXXIV-V, 1982: 219-223; L.N.W. Flanagan, «Steelyards and steelyard weights, Nautical Archaeology, 16, 1987: 249; B. Kaeser. Schnellwaage und laufgewich, en Romischen im Antikenmuseum, Berlin, 1979: 87-89; W. H. Manning, Catalogue of the romano-british iron tools, fittings and weapons in the British Museum. Londres, 1985.

Las piezas más espectaculares conocidas de la Península pueden verse en Los Bronces Romanos en España, Madrid, 1990: 341-343.

Un estudio completo de las posibilidades de uso de las romanas y diversas fórmulas para calcular los pesos de los "aequipondia», de acuerdo con la longitud de sus brazos, en D. Kent Hill, "When the romans went shopping", Archaeology, 5, 1, 1952: $51-52$.

T. P., 1991, $\mathrm{n}^{\mathrm{9}} 48$ 


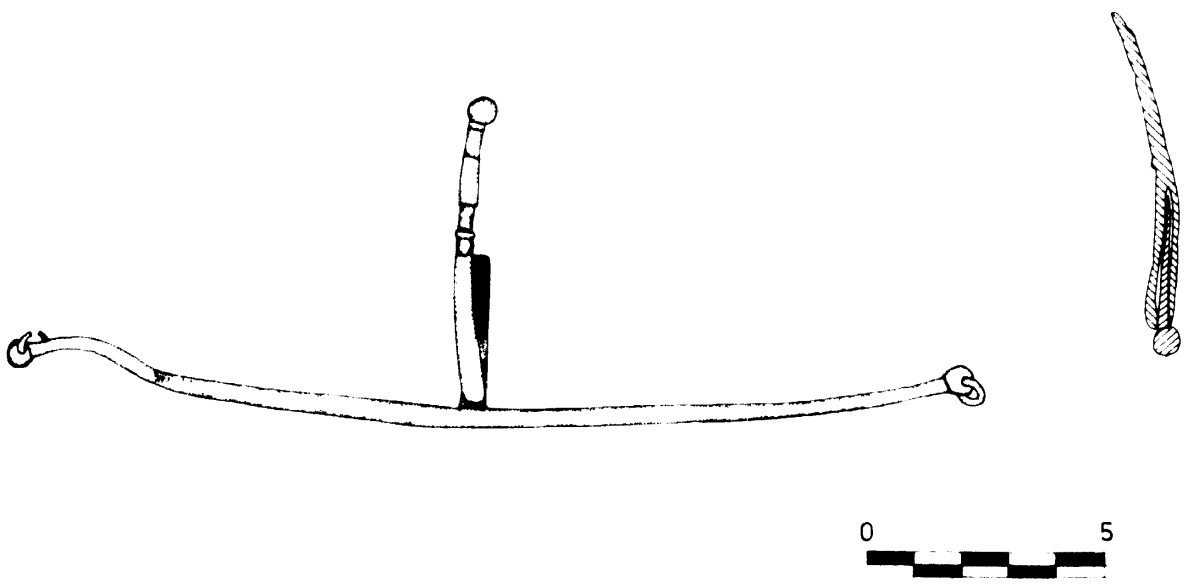

FIG. 5.-Fiel y barra de una "momentana» del Museo de Sevilla.

utilidad casi exclusivamente al peso de objetos pequeños, pero valiosos o especialmente delicados, sobre todo en el comercio itinerante. Su utilización "in situ" conllevaba lógicamente menos problemas, y tenía la ventaja de su mayor posibilidad de exactitud y control. Las que acabarán llamándose "romanas", "campanas" en un principio, por la región de Italia donde habían comenzado a emplearse, eran, por el contrario, muy fácilmente transportables, su lectura directa, y por tanto mucho más rápida, y no necesitaban más que un solo contrapeso, "aequipondium», que corre todo a lo largo de la barra, estando su valor de acuerdo con la longitud del brazo del que colgaba el producto a pesar, valor que podía cambiar con solo hacer girar la barra.

Pertenecientes a balanzas tenemos en el Museo de Sevilla distintos elementos. Por un lado la barra completa y el fiel de lo que habría que considerar una "momentana" o "statera" de bronce, como llama S. Isidoro a estos ejemplares de pequeño tamaño, que decía servían para pesar moneda (Fig. 5).

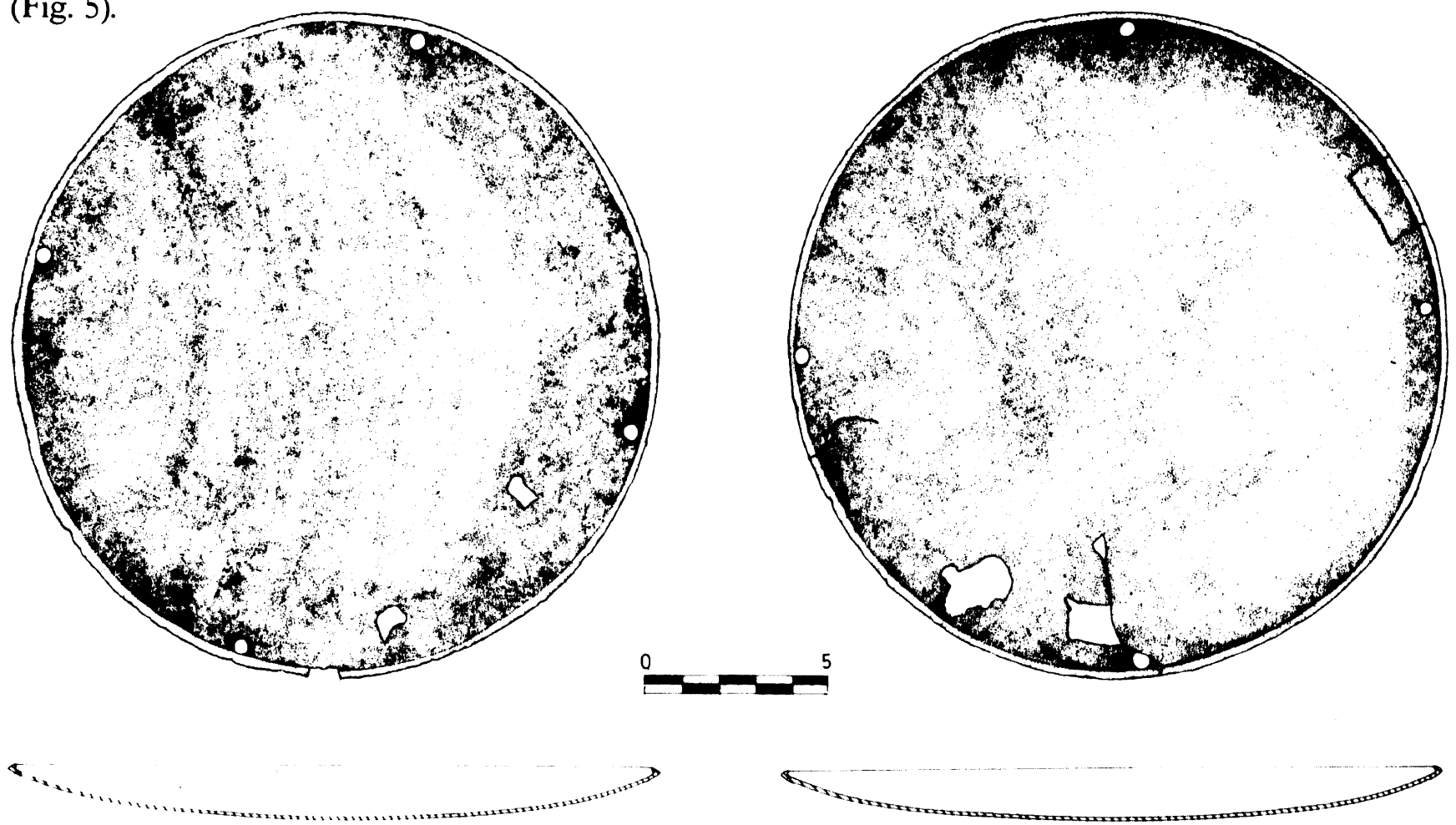

FIG. 6.-Platillos de una balanza del Museo de Sevilla. 

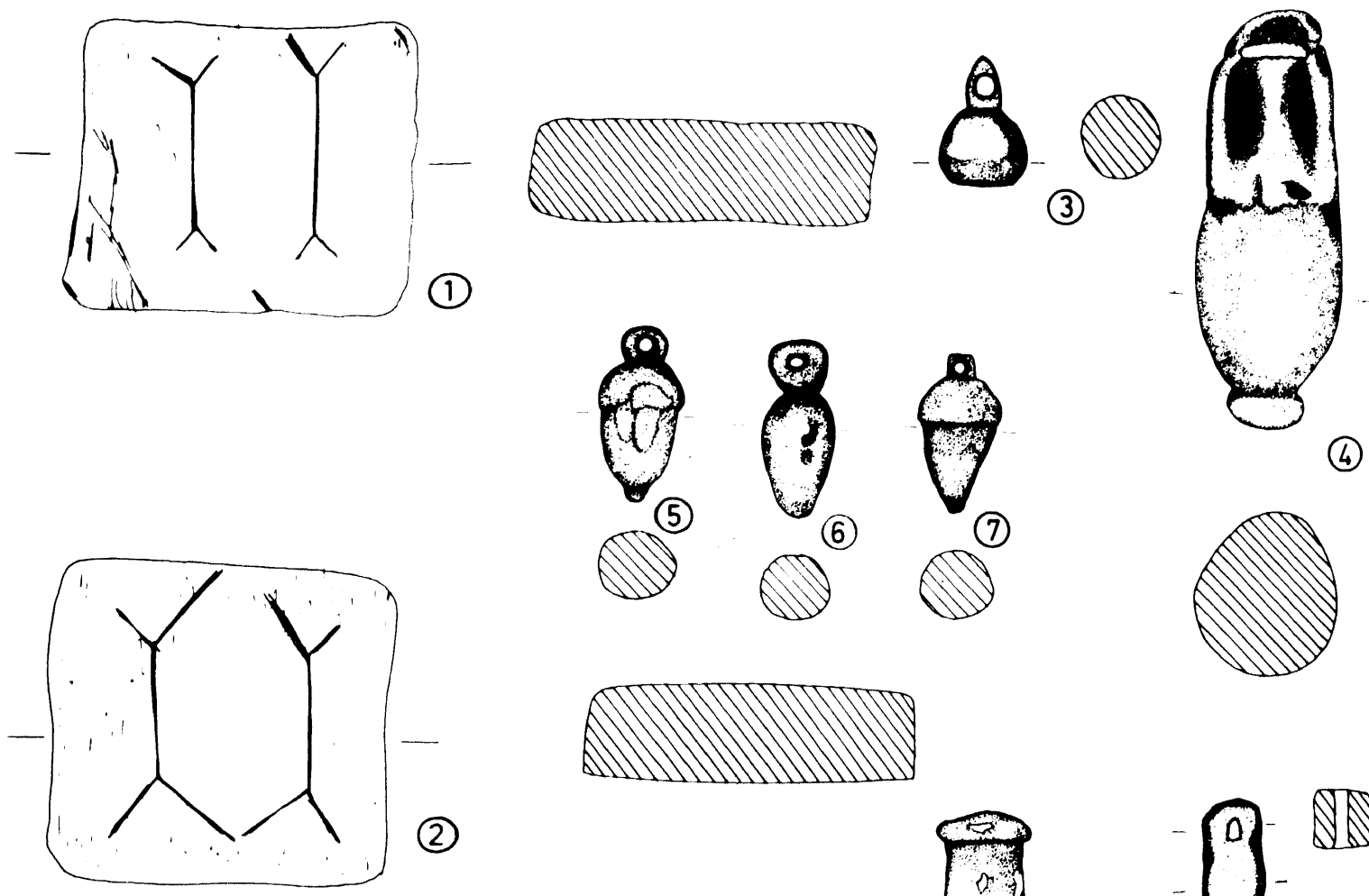
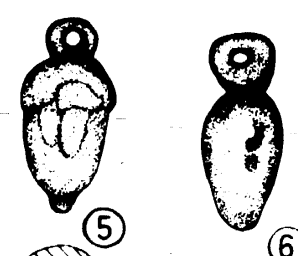

(6)

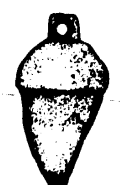

(7)

(4)

(2)
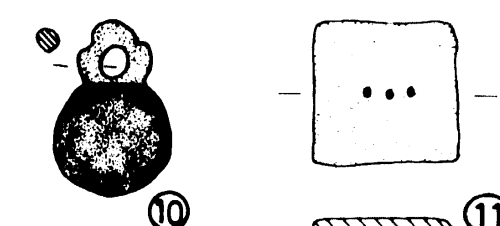

(1)

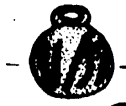

(12) (12)

(11)

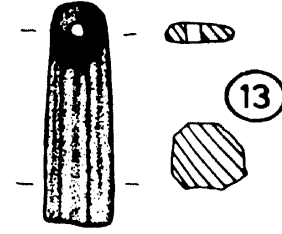

(13)
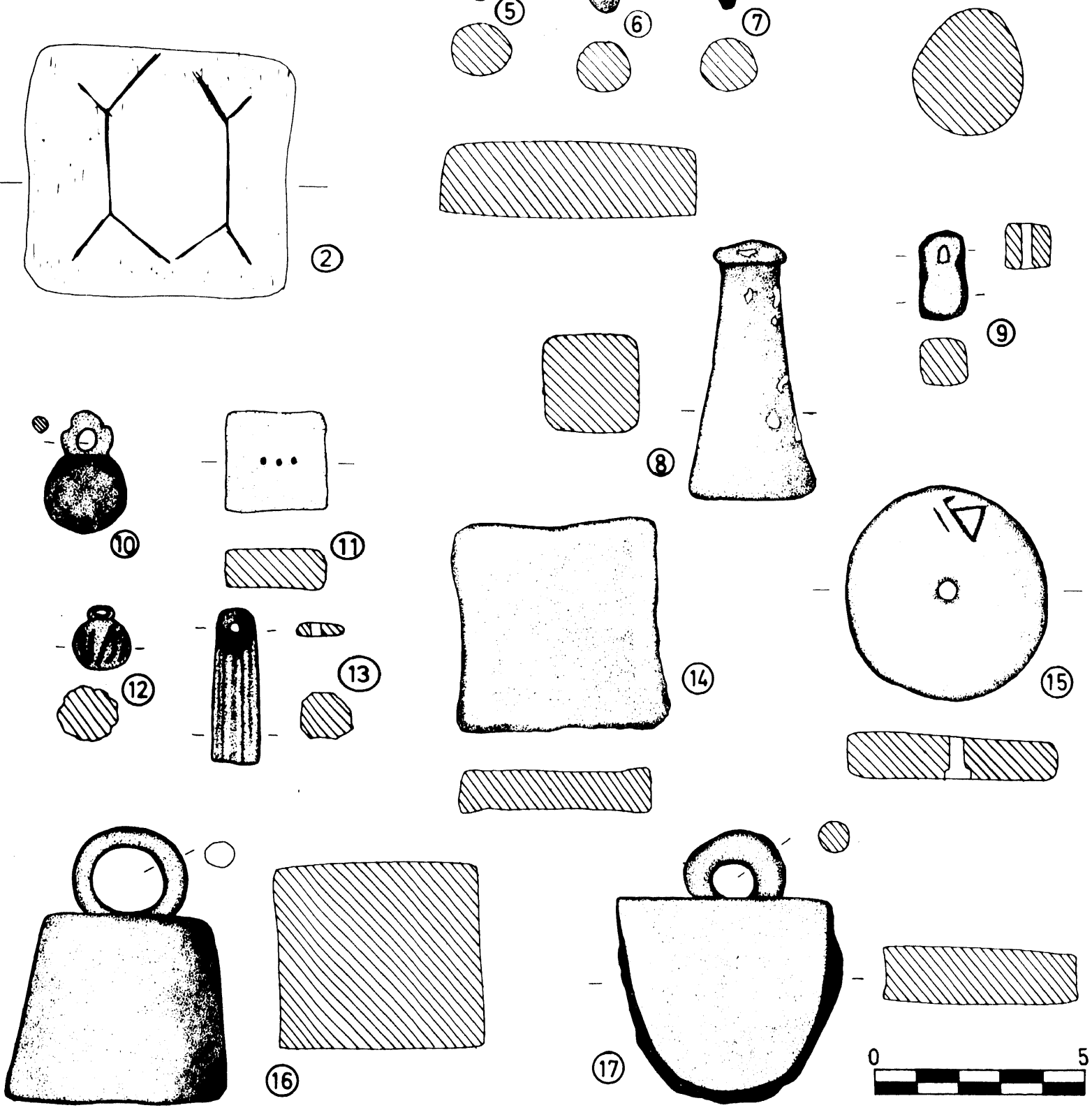

(16)
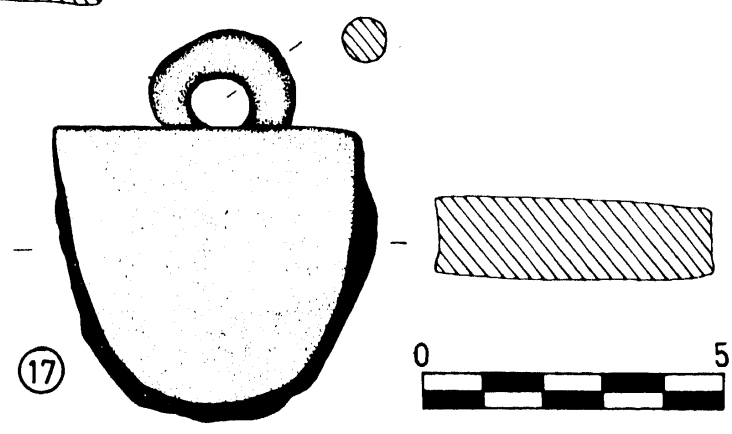

Fig. 7.-Diversas pesas y contrapesos del Museo de Sevilla. 
A un ejemplar algo mayor, pero que creemos habría que considerar todavía como "momentana", pertenecen dos platillos iguales que hemos encontrado también en el mercadillo de antigüedades y depositado en nuestro Museo. Carecen, como es lógico, de procedencia, aunque es fácil suponerla en algún lugar de la provincia, tan saqueada por las excavaciones clandestinas. Son de bronce, de forma ligeramente cóncava, con el labio engrosado. Junto al borde presenta cuatro perforaciones diametralmente opuestas para permitir su suspensión de los extremos de la barra, seguramente por medio de cadenillas. Su diámetro es de $177 \mathrm{~mm}$. Su conservación buena, aunque con algunas lagunas y fracturas de pequeño tamaño, casi insignificantes, y una reparación o añadido en el borde de uno de ellos (Fig. 6).

Al servicio sin duda de una "trutina", balanza de mayor tamaño que la «momentana", debieron estar los dos contrapesos de forma paralepipédica que, con los números de inventario IG 157 y 158 , se guardan desde hace años en nuestro Museo, procedentes de Itálica. Son de plomo y tienen grabada, incisa sobre una de sus caras mayores, la marca de su valor, el mismo en los dos casos, II (libras), siendo su peso real actual en gramos de 620 y 612, es decir, algo menos de lo que parecería correcto, teniendo en cuenta que la libra equivalía a 327 gr. Estaría más de acuerdo con la llamada libra céltica, que solo llegaba a los $309 \mathrm{gr}$.

A otra "trutina", más que a una romana, aunque también para éstas parece adecuada, por la anilla de que dispone en la parte superior, podría haber pertenecido otro contrapeso, éste de bronce y de forma troncopiramidal, con base cuadrada, $50 \mathrm{~mm}$. de lado, y $823 \mathrm{gr}$. de peso, lo que equivaldría a 2.5 libras romanas. Procede de Las Canteras Altas (Osuna, Sevilla), y se halla registrado en el Museo con el número RE. 9027.

Tenemos además en el Museo una numerosa serie de contrapesos (Fig. 7) casi todos de plomo, algunos de bronce, de las formas más diversas, en su mayor parte procedentes también del mercado de antigüedades, los cuales presentamos aquí en su conjunto. Son en total 216 piezas. De ellas, 46 , el $21.3 \%$, de forma cuadrada; 42 , el $19.44 \%$, circulares; 28 , el $13 \%$, cúbicas, y otras tantas en forma de bellota; 20 , el $9,26 \%$, troncocónicas o troncopiramidales, e igual número de anulares; 11 , el $5.10 \%$, rectangulares; y la veintena restante informes o de formas diversas, de hoja, de corazón, de pera, de ánfora, y otras. A una pieza que presenta forma de dado, no sabemos si considerarla como pesa o como auténtica ficha de juego.

A todas ellas las hemos pesado por si podía observarse algún tipo de relación o agrupamiento alrededor de determinados valores. Los resultados han sido completamente negativos, pues la sucesión de pesos, entre los 1.69 gr. del más pequeño, y los 332 de la pieza de mayor tamaño de esta serie, excluidas las descritas en un principio, es continua. A esta última, e incluso a otro par de ellas que alcanzan o sobrepasan los 300 gr., podríamos equipararlas con la libra. Y entre los divisores encontrar los que queramos, pues, como decíamos, la serie es continua y completamente heterogénea.

Lo que sí es curioso observar es que solo en muy raras ocasiones sobrepasan la libra de peso. Y que la inmensa mayoría no llega a los 100 gr. Que solo 17 piezas, el $7.8 \%$, tienen entre 100 y 200 gr.; solo 6, el $2.8 \%$, entre 200 y 300; y solo 3, las que citábamos al principio, entre 300 y 400 gramos (2).

(2) Nuestro agradecimiento a José Luis Herrera Morilla, del Museo Arqueológico de Sevilla, por los dibujos realizados para este trabajo, llevado a cabo dentro del Plan Andaluz de Investigación. 